\title{
Kebutuhan Afiliasi dan Perilaku Seksual Pranikah pada Mahasiswa
}

\author{
Alifia Satyana \\ Fakultas Psikologi, Universitas Muhammadiyah Malang \\ e-mail: alifiasatyana@gmail.com
}

\begin{abstract}
College students are in early adulthood developmental phase, which individuals usually try to gain closeness by establishing committed relationship to other individuals such as dating. It supposed to lead to premarital sexual behavior. In dating relationships someone usually do direct contact with his/her partner. These behaviors done to meet the need for attention, support and affection called the needs of affiliation. The purpose of this study was to determine the correlation between the needs of affiliation and premarital sexual behavior in college students. Research subjects were 150 college students who are dating, collected by quota sampling technique, and analyzed by Pearson's product moment correlation method. The results showed correlation coefficient $(r)$ of 0.180 and significant value of $0.014<0.05$, means that there is positive significant correlation between the needs of affiliation and premarital sexual behavior in students who are dating.
\end{abstract}

KEYWORS Affiliation, premarital sexual behavior, student.

CITATION Satyana, A. (2019). Kebutuhan afiliasi dan perilaku seksual pranikah. Cognicia, 8, (1), 157-169.

Sebagian besar manusia pada usia dewasa awal akan mencari dan menemukan pasangan hidup, sehingga akan ada upaya-upaya yang dilakukan untuk mencapai tujuan tersebut, salah satunya adalah menarik perhatian lawan jenis. Baik pria maupun wanita yang beranjak dewasa akan melewati masa dalam pencarian pasangan. Hal ini terjadi karena masa beranjak dewasa merupakan kerangka waktu dimana individu aktif secara seksual dengan kondisi belum menikah. Kondisi ini menyebabkan adanya saat dimana seks bebas lebih lazim dilakukan oleh individu yang beranjak dewasa dibanding orang dewasa muda Lefkowitz \& Gillen(2006). 
Riset Strategi Nasional Kesehatan Remaja yang dilakukan oleh Departemen Kesehatan tahun pada tahun 2008 ditemukan sekitar 54 persen remaja mengaku melakukan hubungan seks sebelum nikah. Kemudian meningkat berdasrakan survei yang dilakukan KPAI dan Kementerian Kesehatan Rpublik Indonesia di tahun 2008 menyebut 63 persen remaja di beberapa kota besar di Indonesia telah melakukan seks pranikah. Data dari Survey Demografi dan Kesehatan Indonesia (SDKI) 2017 mengungkap sekitar 2 persen remaja telah melakukan hubungan seksual sebelum menikah dan 11 pesen mengaku mengalami kehamilan tidak diinginkan. Remaja yang aktif berhubungan seksual semakin meningkat dari tahun ke tahun, seiring dengan kondisi tersebut dengan melakukan kegiatan seksual maka semakin meningkat pula jumlah gadis yang tidak perawan.

Riset BKKBN tahun 2010, 51 persen remaja kehilangan kegadisannya dan telah aktif secara seksual. Data tersebut seiring dengan pengakuan Guru Besar Ilmu Obstetri dan Ginekologi Fakultas Kedokteran Universitas Indonesia Prof Biran Affandi dalam diskusi kerja sama antara Bayer and Asian Pasific Council on Contraception (APCOC) data tahun 2010 terungkap remaja di perkotaan 51 persen sudah berhubungan seksual alias tidak perawan lagi. Di pedesaan, sebanyak 41 persen remaja juga sudah berhubungan seksual. Fenomena banyaknya gadis yang tidak lagi virgin menunjukan tingginya aktivitas seksual pada usia tersebut, baik laki-laki maupun perempuan. Kondisi tersebut terjadi pula pada mahasiswa.

Riset yang dilakukan oleh Lembaga Studi Cinta dan Kemanusiaan serta Pusat Pelatihan Bisnis dan Humaniora pada tahun 2002 menemukan fakta di 16 perguruan tinggi di kota Yogyakarta, 97,05\% dari responden itu mengaku kehilangan keperawanannya dalam periodisasi waktu kuliahnya. Hasil penelitian BKKBN tahun 2010 di kota gudeg itu menunjukkan 37 persen mahasiswanya menikah akibat hamil diluar nikah. Hasil tersebut menunjukkan bahwa selama periodisasi perkuliahan, mahasiswa melakukan hubungan seksual pranikah. Adanya kondisi tersebut menunjukkan adanya krisis yang menyebabkan mahasiswa melakukan hubungan seksual sebelum menikah.

Perilaku seksual pra-nikah yang dilakukan mahasiswa sudah sangat memprihatinkan, mengingat peran mahasiswa yang begitu besar dalam kehidupan bangsa di masa mendatang, maka mahasiswa tidak hanya dituntut untuk memiliki wawasan yang luas, kemampuan akademik yang lebih tinggi, namun juga karakter dan moral yang baik pula.

Mahasiswa dinilai sebagai suatu kelompok yang rentan dan aktif terlibat dalam perilaku seksual pranikah Uecker (2015). Sejumlah 84\% mahasiswa 
mengaku mengalami dampak fisik karena hubungan seksual pranikah yakni merasa dorongan hasrat yang kuat untuk memuaskan diri sendiri dengan onani/masturbasi, ada pula yang mengalami luka setelah melakukan hubungan seksual. Sedangkan dampak psikologis meliputi perasaan cemas, depresi, takut, merasa berdosa, kemudian merasa bersalah kepada orangtua setelah melakukan perilaku seks pranikah Ardi (2014).

Menurut Suyanto \& Ariadi (2004) berdasarkan sifatnya kontak sosial dibagi menjadi dua, yakni primer dan sekunder. Bersifat primer jika kontak sosial itu terjadi secara langsung (face to face) atau ada hubungan fisikal, sekunder jika hubungan itu terjadi melalui perantara orang atau media lainnya atau dengan kata lain gejala sosial tersebut terjadi tanpa harus menyentuh orang lain Soekanto (2002). Maka dapat dikatakan bahwa seseorang yang memiliki kebutuhan afiliasi tinggi lebih cenderung melakukan kontak primer (langsung) baik tatap muka maupun bersentuhan, seperti pendapat Peplau \& Perlman (1982), bahwa kebutuhan afiliasi dapat terpenuhi dengan cara mengadakan kontak sosial seperti menghubungi atau mengunjungi oranglain.

Hill (Baron \& Byrne, 1997) seseorang yang memilki kebutuhan afiliasi tinggi juga akan memunculkan perilaku sesuai keempat aspek dari kebutuhan afiliasi yaitu Positive Stimulation (ingin memiliki hubungan erat dengan orang lain), Emotional Support (menunjukan apa yang ia alami dengan bercerita mengenai dirinya sehingga orang lain akan memberikan dukungan), Social Comparison (membandingkan dirinya dengan orang lain) dan Attention (menarik perhatian). Sejalan dengan kondisi individu pelaku seksual sebelum adanya ikatan pernikahan yang cenderung menginginkan kedekatan, kontak secara langsung, untuk mendapatkan kepuasan akan kebutuhannya tersebut.

Pada penelitian sebelumnya menggambarkan bentuk perilaku yang tampak namun tidak digali lebih mendalam mengapa faktor-faktor tersebut muncul, sehingga diharapkan penelitian yang akan dilakukan ini dapat mengungkap penyebab terjadinya perilaku seksual pra-nikah. Mengingat dasar dari terbentuknya perilaku seseorang berasal dari hierarki of need, Maslow (Alwisol, 2009).

Erikson (dalam Papalia, Old, \& Feldman, 2008) mengemukakan, pada tahap dewasa awal ini, individu berusaha memperoleh kedekatan yang dapat diwujudkan melalui komitmen terhadap suatu hubungan dengan orang lain, baik dalam hubungan pacaran atau menikah Dalam hubungan pacaran seseorang akan melakukan kontak langsung secara primer maupun sekunder untuk memperoleh hubungan yang intens dan dekat. Kalat (2010) Pada masa dewasa 
hormon seks mengaktifasi perilaku seksual yang disebabkan oleh aktivitas di area praoptik medial dan hipotalamus anterior. Hormon tersebut menyiapkan sel untuk melepaskan dopamin sebagai bentuk respon kegairahan seksual sehingga secara alamiah individu akan tertarik dengan lawan jenis. Ketertarikan mengundang seseorang untuk menjalin suatu kontak langsung secara terus menerus sehingga terjadi hubungan romantis, dimana dalam hubungan romantis tersebut berkembang bentuk-bentuk perilaku seksual sejalan dengan meningkatnya dorongan seksual (Andayani \& Setiawan, 2005).

Berdasarkan uraian di atas, peneliti berasumsi bahwa kebutuhan berafiliasi yang tinggi dan tidak terkontrol menyebabkan mahasiswa mengesampingkan unsur internal yang ada pada dirinya berupa nilai-nilai moral kehidupan yang didapatkan dari orangtua, dan lingkungan tempat ia berada. Bentuk afiliasi tersebut berupa perasaan sayang, takut akan kehilangan, menjalin hubungan dekat. Adanya kondisi ini mengacu pada kebutuhan akan hubungan sosial atau kedekatan dengan individu lain. Seseorang dengan kebutuhan afiliasi tinggi cenderung menjalin hubungan dekat untuk mendapatkan dukungan sehingga merasa aman. Sesuai dengan tugas perkembangan seorang dewasa awal ketika menjalin hubungan dekat dengan lawan jenis akan mengalami ketertarikan, hal ini akan mengundang seseorang tersebut untuk menjalin hubungan romantis. Dalam hubungan romantis akan berkembang bentuk-bentuk perilaku seksual seiring dengan meningkatnya dorongan seksual seseorang. Dengan adanya kondisi tersebut penulis menduga bahwa kebutuhan afiliasi tinggi memiliki hubungan dengan perilaku seksual pranikah.

Adanya kondisi tersebut, peneliti tertarik dan merasa penting untuk melakukan penelitian yang bertujuan untuk mengetahui hubungan antara kebutuhan afiliasi dengan perilaku seksual pra-nikah pada mahasiswa. Manfaat penelitian ini adalah untuk mengetahui gambaran hubungan kebutuhan afiliasi dengan perilaku seksual pra-nikah pada mahasiswa di Kota Malang. Selanjutnya untuk manfaat teoritis yakni dapat dijadikan referensi bagi peneliti lain yang tertarik untuk membahas perilaku seksual pranikah dan kebutuhan afiliasi.

Hipotesis penelitian ini adalah terdapat hubungan antara kebutuhan afiliasi dengan perilaku seksual pranikah pada mahasiswa. Semakin tinggi kebutuhan afiliasi maka semakin tinggi perilaku seksual pranikah dan begitu pula sebaliknya, semakin rendah kebutuhan afiliasi maka semakin rendah perilaku seksual pranikah.

\section{Metode}


Kebutuhan afiliasi adalah kebutuhan individu untuk dekat dengan individu lain yang bertujuan untuk mendapatkan dukungan, membentuk pertemanan, bersosialisasi, kerja sama, berkomunikasi, berinteraksi secara dekat dengan orang lain. Jumlah item valid sebanyak 29 item dari 58 yang telah di lakukan uji coba. Indeks validitas 0,373 - 0,648 dengan indeks 0,910 reliabilitas Perilaku seksual adalah perilaku berhubungan fisik yang didorong oleh hasrat seksual berupa pelukan, meraba, hingga berhubungan intim untuk mendapatkan kenikmatan dan dilakukan oleh pasangan yang belum memliki ikatan sah baik secara hukum, agama, kepercayaan, norma, dan adat yang berlaku. Instrumen penelitian menggunakan skala perilaku seksual pranikah disusun menggunakan metode Thurstone Scale atau Interval Tampak-setara (Method of equal appearing intervals) menghasilkan 14 item valid dan reliabel dengan rentang indeks kesepakatan (Q) 0 - 1,954. Sampel yang digunakan dalam penelitian ini berjumlah 150 mahasiswa dan mahasiswi di Kota Malang.

\section{Hasil}

Hasil di tabel 3 menunjukkan bahwa mahasiswa perempuan yang memiliki kebutuhan afiliasi tinggi lebih banyak dibandingkan laki-laki. Sedangkan perilaku seksual pranikah tinggi lebih dominan di kategori laki-laki.

Tabel 2. Deskripsi Kebutuhan Afiliasi dan Perilaku Seksual Pranikah

\begin{tabular}{llllll}
\hline & Kategori & Interval T-Score & N & Laki-laki & $\begin{array}{c}\text { Perempua } \\
\text { n }\end{array}$ \\
\hline Kebutuha & Tinggi & T-Score $\geq 50$ & $73(48,7 \%)$ & $18(38,3 \%)$ & $55(53,4 \%)$ \\
n Afiliasi & Rendah & T-Score $<50$ & $77(51,3 \%)$ & $29(61,7 \%)$ & $48(46,6 \%)$ \\
\hline Total & & & $150(100 \%)$ & $47(100 \%)$ & $103(100 \%$ \\
\hline Perilaku Seksual & Tinggi & T-Score $\geq 50$ & $59(39,3 \%)$ & $25(53,2 \%)$ & $34(33,1 \%)$ \\
Pranikah & Rendah & T-Score $<50$ & $91(60,7 \%)$ & $22(46,8 \%)$ & $69(66,9 \%)$ \\
\hline Total & & & $150(100 \%)$ & $47(100 \%)$ & $103(100 \%$ \\
\hline
\end{tabular}

Berdasarkan analisis data yang dilakukan, diperoleh koefisien korelasi dengan nilai

(r) 0,180, sedangkan nilai signifikan (p) sebesar 0,014 < 0,05 yang menunjukkan bahwa ada hubungan positif dan signifikan antara kebutuhan afiliasi dengan perilaku seksual pranikah. Pernyataan tersebut lebih jauh menerangkan bahwa semakin tinggi kebutuhan afiliasi mahasiswa yang berpacaran, maka semakin 
tinggi pula perilaku seksual pranikah. Begitu pula sebaliknya semakin rendah kebutuhan afiliasi subjek, maka semakin rendah pula perilaku seksual pranikah. Kemudian pada nilai regresi atau $r$ square $\left(r^{2}\right)$ adalah 0,320 yang artinya kebutuhan afiliasi menyumbang 32\% terhadap perilaku seksual pranikah, sedangkan sisanya $68 \%$ dipengaruhi oleh aspek-aspeklain.

Penelitian ini menunjukkan adanya hubungan positif antara kebutuhan afiliasi dengan perilaku seksual pranikah pada mahasiswa yang berpacaran. Sehingga dapat dikatakan bahwa semakin tinggi kebutuhan afiliasi maka semakin tinggi pula kecenderungan perilaku seksual pranikah pada mahasiswa. Hal ini menjadikan hipotesis penelitian yang menyatakan bahwa ada hubungan antara kebutuhan afiliasi dengan perilaku seksual pranikah dapat diterima.

\section{Diskusi}

Kebutuhan afiliasi memiliki korelasi positif dengan perilaku seksual pranikah, sesuai dengan hipotisis yang diajukan oleh peneliti sebelumnya, bahwa kebutuhan afiliasi merupakan salah satu komponen dari terbentuknya kepribadian seseorang berdasarkan need. Kebutuhan afiliasi yang tinggi itu sendiri menstimulus seseorang untuk memiliki hubungan yang dekat dengan orang lain baik teman, keluarga, maupun pasangan. Seperti yang dikemukakan oleh Baron \& Bryne (2003) bahwa dalam kebutuhan berafiliasi mengandung hubungan pertemanan, bersosialisasi, interaksi secara dekat, bekerjasama dan komunikasi dengan orang lain dengan cara besahabat, maupun jatuh cinta. Kebutuhan seseorang akan afiliasi yang tinggi mendorong seseorang untuk membentuk dan mempertahankan komunikasi yang akrab antar individu, apabila tidak terpenuhi menyebabkan adanya rasa kesepian dan terisolasi pada tahap perkembangan sebagai mahasiswa. Hal ini terjadi karena ada masa dimana dewasa awal mengalami perasaan takut dikucilkan atau terisolir sehingga menyebabkan seseorang berusaha memiliki hubungan yang intim dan menunjukan keterikatan dengan individu lain Santrok (2012). Kemudian demi mempertahankan hubungan dekat dan kepuasan dibutuhkan pengorbanan yang dilakukan dalam relasi antar individu. Salahsatu hal yang terkait dengan kepuasan dalam berhubungan adalah seksualitas, terutama dalam konteks relasi diadik Strachman \& Gable (2006). Sejumlah 39,3\% subjek memiliki perilaku seksual pranikah tinggi, sedangkan subjek dengan perilaku seksual rendah sebanyak 60,7\%. Maka subjek yang berperilaku seksual pranikah tinggi lebih sedikit jumlahnya dibandingkan dengan subjek yang 
berperilaku seksual pranikah rendah, adapun selisih jumlah tersebut sebanyak $21,4 \%$. Dengan selisih yang tidak terlalu jauh, perilaku seksual sendiri terjadi akibat adanya dorongan baik eksternal maupun internal dari individu. Penelitian yang dilakukan oleh Anggara (2016) tentang perilaku seksual yang ada pada mahasiswa menunjukkan $29,27 \%$ remaja merasa ingin dicintai atau diterima oleh lawan jenis. Dan 3,25\% pernah melakukan hubungan seksual karena alasan merasa diolok - olok karena masih perjaka atau perawan. Hal ini menunjukkan bahwa kebutuhan akan dukungan positif yang diberikan oleh teman sebaya maupun lingkungan menjadi salah satu faktor yang mengakibatkan individu melakukan hubungan seks sebelum adanya ikatan pernikahan.

Berdasarkan hasil penelitiaan ini diketahui 48,7\% subjek yang memiliki kebutuhan afiliasi tinggi, sedangkan 51,3\% dari jumlah subjek yang memilki kebutuhan afiliasi rendah. Dengan kata lain hampir setengah dari jumlah subjek mahasiswa memiliki kebutuhan afiliasi yang tinggi. Hal ini sesuai dengan temuan Musdalifa (2017) bahwa 38,80\% subjek memilki kebutuhan afiliasi tinggi. Sehingga dapat dikatakan hampir setengah dari mahasiswa yang berpartisipasi dalam penelitian ini memiliki kebutuhan untuk berhubungan secara baik dan akrab dengan orang-orang disekitarnya baik teman maupun pasangan. Hal tersebut terjadi karena adanya keinginan untuk membentuk suatu hubungan interpersonal (keintiman). Jika keintiman antar individu sudah terbentuk maka akan timbul rasa saling percaya dan saling membutuhkan satu sama lain dimana semua itu merupakan bagian dari kebutuhan afiliasi Rinjani \& Firmanto (2013). Disamping itu individu yang memiliki kebutuhan afiliasi tinggi akan lebih suka bersama orang lain dari pada sendirian, sering berinteraksi, ingin disukai dan diterima, menyenangkan hati orang lain, menunjukkan dan memelihara sikap setia terhadap teman, serta mencari persetujuan dan kesepakatan dari individu lain.

Hasil penelitian ini menerangkan bahwa jumlah subjek mahasiswa perempuan yang memiliki kebutuhan afiliasi tinggi lebih banyak 15,1\% dibandingkan subjek mahasiswa laki-laki. Hal ini sependapat dengan penelitian yang dilakukan oleh Nupus (2017) yang menyatakan bahwa ratarata kebutuhan afiliasi subjek perempuan lebih tinggi sebanyak 11,4 dibandingkan laki-laki. Kondisi tersebut juga sejalan dengan pendapat Ekasari \& Hartati (2014) dalam penelitiannya terhadap subjek perempuan di pesantren, sebanyak 66,67\% subjek dalam kategori afiliasi tinggi, dan 28,99\% dalam kategori sangat tinggi. 
Secara biologis wanita mengalami masa dimana hasrat seksual tinggi yaitu pada masa periovulation (waktu terjadi ovulasi) yang tidak terjadi setiap hari ataupun terus menerus. Sedangkan laki-laki tidak memiliki spesifik waktu sehingga hasrat seksual dapat muncul kapan saja Kalat (2010). Dapat disimpulkan rata-rata kebutuhan afiliasi subjek perempuan memang ada pada kategori tinggi. Adanya kondisi tersebut karena perempuan dianggap memiliki sensitifitas dan regulasi emosi yang lebih dan membuat perempuan membutuhkan dukungan lebih pula dibandingkan laki-laki Ratnasari \& Suleeman (2017). Perempuan mempunyai keunikan untuk membangun hubungan dengan orang disekitarnya melalui emosi, kemudian perempuan juga identik dengan seseorang yang lebih mengedepankan perasaan dalam menghadapi permasalahan. Pernyataan tersebut menjadikan perempuan yang dinilai memiliki kebutuhan afiliasi tinggi lebih mendambakan adanya hubungan ramah dan akrab, kedekatan terhadap individu lain, dukungan positif terhadap teman sebaya maupun pasangannya dibandingkan laki-laki sehingga tidak merasa terkucilkan maupun terisolir.

Temuan oleh Rahardjo, Saputra, Damariyanti, Ayuningsih \& Siahay (2017) maupun Rahman, Rahman, Ismail, Ibrahim, Ali, Salleh \& Wan (2012) menunjukkan bahwa mahasiswa pria lebih bersikap positif terhadap prilaku seksual pranikah dibandingkan mahasiswa perempuan, selain itu pria juga cenderung lebih bebas dalam melakukan perilaku seksual pranikah. Hasil penelitian tersebut sependapat dengan penelian ini yang menerangkan bahwa 20,1\% subjek mahasiswa laki-laki cenderung memiliki perilaku seksual pranikah dibandingkan perempuan. Kalat (2010) Secara biologis puncak kenikmatan seksual pada laki-laki adalah ketika kadar testosteron berada pada level tinggi pada usia 15 - 25 tahun. Sedangkan perempuan hanya mengalami puncak hasrat seksual pada masa periovulation (waktu terjadi ovulasi). Hal tersebut menyebabkan perilaku seksual pada pria lebih mudah dipicu dibandingkan perempuan. Dalam kondisi ini maka subjek mahasiswa laki-laki cenderung lebih mudah untuk melakukan maupun memiliki perilaku seksual sebelum adanya ikatan pernikahan dibandingkan subjek mahasiswa perempuan. Dalam budaya timur keperjakaan dan keperawanan masih merupakan suatu hal yang penting, namun yang lebih ditekankan adalah keperawanan. Seorang wanita yang belum menikah namun sudah tidak perawan akan lebih dipermasalahkan dan menjadi momok dibanding laki-laki yang tidak perjaka. Adanya kondisi tersebut menjadikan laki-laki merasa memiliki resiko yang lebih kecil dalam melakukan hubungan seksual pranikah dibandingkan 
perempuan Setiawan \& Nurhidayah (2008).

Berdasarkan analisa yang telah dilakukan, hasil penelitian ini menunjukkan bahwa secara umum mahasiswa berpacaran di Kota Malang sudah pernah melakukan perilaku seksual yaitu berpegangan tangan 81,3\%, duduk berdampingan 98\%, merapatkan tubuh dengan merangkul sebanyak $78 \%$, merapatkan tubuh dengan merangkul pinggang sebanyak 62,67\%, mencium rambut $54,67 \%$, dicium kening 70,67\%, mencium bibir 48,67\%, dicium bibir $49,3 \%$, ciuman leher sebanyak $32,67 \%$, ciuman pada sebagian besar tubuh diluar pakaian sebanyak $28 \%$, ciuman pada sebagian besar tubuh tanpa menggunakan busana sebanyak 25,3\%, saling menempelkan alat kelamin $20,67 \%$, saling menggesek- gesekan alat kelamin sebanyak 18\%, kemudian melakukan hubungan seksual (bersenggama) sebanyak 10\%. Dengan adanya pemaparan tersebut dapat diketahui keberagaman jenis perilaku seksual yang dilakukan oleh mahasiswa. Semakin jauh jenis perilaku seksual jumlah subjek yang terlibat semakin kecil dikarenakan mayoritas subjek masih mempertimbangkan resiko dari perilaku seksual pranikah yang ekstrim, misalnya penularan penyakit, ataupun kehamilan Setiawan \& Nurhidayah (2008). Kebutuhan afiliasi menyumbang 32\% sehingga terjadi perilaku seksual pranikah. Kemudian sisanya $68 \%$ dapat dipengaruhi oleh aspek-aspek lain, misalnya; sikap terhadap perilaku seksual pranikah, komitmen hubungan, lingkungan dan budaya Rahardjo, Saputra, Damariyanti, Ayuningsih \& Siahay (2017).

\section{Kesimpulan}

Hasil penelitian ini menerangkan bahwa ada hubungan positif antara kebutuhan afiliasi dengan perilaku seksual pranikah pada mahasiswa yang berpacaran. Artinya semakin tinggi kebutuhan afiliasi yang dimiliki maka semakin tinggi pula kecenderungan perilaku seksual pranikah pada mahasiswa yang berpacaran dan begitu pula sebaliknya apabila kebutuhan afiliasi yang dimiliki rendah maka semakin rendah pula perilaku seksual pranikah pada mahasiswa, sehingga hipotesis penelitian ini dapat diterima.

Implikasi penelitian ini, bagi mahasiswa diharapkan dapat mengatur kegiatan selama masa perkuliahan. Mengisi waktu luang dengan kegiatan positif seperti mengikuti UKM atau organisasi lainnya, berinteraksi dengan banyak orang, membangun hubungan interpersonal dengan teman ataupun sahabat sehingga kebutuhan afiliasi dapat terpenuhi oleh individu-individu yang positif, kemudian perhatian terhadap perilaku seksual dapat dihindari 
pula. Selanjutnya dapat menjadi agen perubahan dengan memberikan pengaruh positif, menanamkan nilai moral, dan rasa peduli terhadap teman di lingkungan perkuliahan. Bagi civitas akademika di berbagai kampus diharapkan turut serta berperan dalam mencegah terjadinya perilaku seksual dengan memberikan pengetahuan dan pengawasan terkait perilaku seksual pranikah sejak awal perkuliahan sehingga dapat mengurangi akibat-akibat negatif perilaku tersebut. Selanjutnya bagi orangtua diharapkan menjalin komunikasi dengan baik untuk mengetahui kehidupan perkuliahan yang dijalani oleh anaknya sehingga anak akan merasa terpantau dan memiliki tanggungjawab terhadap dirinya, selain itu perhatian yang terpenuhi oleh orangtua diharapkan dapat mengurangi kebutuhan afiliasi terhadap pacar. Sedangkan bagi peneliti selanjutnya diharapkan dapat menemukan metode baru sehingga membuat subjek lebih bertanggung jawab untuk mengisi dengan jujur setiap pernyataan yang disajikan. Kemudian untuk memperkaya pembahasan terkait perilaku seksual pranikah peneliti dapat mengkaji faktorfaktor lain yang berhubungan sehingga akan didapatkan pengetahuan yang lebih mendalam.

\section{Referensi}

Abraham, J., \& Rahardjo, W. (2015). Psychopathy, sexual values dimensions, and premarital sexual behavior among urban unmarried adolescents. Procedia Social and Behavioral Sciences, 165, 2-11. doi: 10.1016/ j.sbspro. 2014.12.598.

Agusdwitanti, H., \& Tambunan, S. M. (2015). Kelekatan dan intimasi pada dewasa awal. Jurnal Ilmiah Psikologi, 8(1).

Alwisol. (2009). Psikologi kepribadian edisi revisi. Malang : UMM Press. . (2014). Psikologi kepribadian. Cetakan ke-14. Malang UMMPress.

Amir, M. T. (2016). Inovasi pendidikan melalui problem based learning. Jakarta : Prenada Media.

Andayani, T., \& Setiawan, I. (2005). Perilaku seksual pranikah dan sikap terhadap aborsi. Jurnal Psikologi, 2,1-9.

Anggara, B. P. N. (2016). Gambaran perilaku seksual pada mahasiswa. Skripsi, Program Studi Psikologi Fakultas Psikologi Universitas Kristen Satya Wacana.

Ardi. N. M. S. (2014). Perilaku seksual remaja mahasiswa fakultas bahasa dan seni universitas negeri surabaya. Jurnal BK UNESA, 4(3).

Arnett, J. J., \& Tanner, J. L. (Eds.). (2006). Emerging adults in America: Coming of age in the 21st century (p. 3). Washington, DC: American Psychological Association.

Azwar, S. (2013). Metode penelitian . Yogyakarta: Pustaka Pelajar.

Badan Koordinasi Keluarga Berencana Nasional (2010). Separo Remaja Surabaya Tak Perawan. Diakses dari https://surabaya.tribunnews.com/2010/11/29 
Cognicia

http://ejournal.umm.ac.id/index.php/cognicia
ISSN 2658-8428

2020, VOL. 8, NO. 1, 157-169

Baron, R. A., \& Byrne, D. (1997). Social psychology, Eight Edition. Massachusettes: Allyn and Bacon. (2003). Psikologi sosial jilid 1. Jakarta: Erlangga.

Bayer dan Asian Pasific Council on Contraception (2017). Terungkap Remaja Di Desa Tak Perawan Lagi, Di Kota Lebih Parah. Diakses dari https://radarmalang.id/2017/10/4

Chaplin, J. P. (2009). Dictionary of Psychology (Terjemahan: Katini K.), Jakarta: PT. Raja Grafindo Persada.

Dewi, T. N., \& Kuncoro, J. (2019). Kebutuhan Berafiliasi, Introversi Kepribadian Serta Ketergantungan Pada Facebook Pada Mahasiswa. Proyeksi: Jurnal Psikologi, 6(2), 68- 77.

Diniaty, A. (2012). Perilaku seks pranikah pada mahasiswa (Studi Kasus Mahasiswa UIN Suska Riau). Marwah: Jurnal Perempuan, Agama dan Jender, 11(2), 1-16.

Duffy, G. K., \& Atwater, E. (2013). Psychology for living.' Adjustment, growth, and behavior today. 11 ed. Inggris: Pearson.

Ekasari, M. D., \& Hartati, S. (2014). Hubungan antara kebutuhan afiliasi dengan kesepian pada remaja di panti asuhan putri aisyiyah dan putra Muhammadiyah Tuntang dan Salatiga. Empati: Jurnal Undip, 3(4), 390-400.

Fretwell, C. E., Lewis, C. C., Hannay, M., \& Colley, M. C. (2017). Need for Affiliation of College Football Fans: A Partial Least Squares (PLS) Path Modeling Approach. Journal of Marketing Development and Competitiveness, 11(3).

Furman, W., \& Shaffer, L. (2011). Romantic partners, friends, friends with benefits, and casual acquaintances as sexual partners. Journal of Sex Research, 48(6), 554-564.

Hall, C. S., \& Lindzey, G. (2004). Teori-teori holistik (organismik-fenomenologis) (terjemahan dari theories of personality oleh Yustinus). Yogyakarta: Kanisius. . (2009). Teori-teori sifat dan behavioristik. Yogyakarta: Kanisius.

Hartaji, D. A. (2012). Motivasi berprestasi pada mahasiswa yang berkuliah dengan jurusan pilihan orangtua. Fakultas Psikologi Universitas Gunadarma.

Hatfield, E., Cacioppo, J. T., \& Rapson, R. L. (1994). Emotional contagion. Studies in Emotion and Social Interaction. Cambridge: Cambridge University Press.

Hurlock, E. B. (1980). Instructor's Manual to Accompany "Developmental Psychology, a Life-span Approach". McGraw-Hill.

Irawati, P.I. Factors affecting the attitude of men's sexual behaviour towards wedlock in teenagers. Indonesia: BKKBN. 2005.

Jersild, A.T. (1995). The psychology of adolescene third edition. New York: The Macmilan. Jufri.

M. (2005). Intensitas mengakses situs seks dan permisivitas perilaku seksual remaja. Jurnal Intelektual. Volume 3.No.2

Kalat, J.W. (2010). Biopsikologi Buku 2 Edisi 9. Jakarta: Salemba Humanika.

Kinsey, A. C., Pomeroy, W. B., Martin, C. E., \& Gebhard, P. H. (1998). Sexual behavior in the human female. Indiana University Press.

Komite Perlindungan Anak Indonesia \& Kemeterian Kesehatan (2014). Remaja di Indonesia Melakukan Seks Pranikah. Diakses dari https://www.kompasiana.com

Kroger, J., \& Marcia, J. E. (2011). The identity statuses: Origins, meanings, and interpretations. 
In Handbook of identity theory and research (pp. 31-53). Springer, New York, NY.

Lefkowitz, E. S., \& Gillen, M. M. (2006). " Sex Is Just a Normal Part of Life": Sexuality in Emerging Adulthood. In Emerging adults in America: Coming of age in the 21st century. (pp. 235-255). American Psychological Association. http://dx.doi.org/10.1037/11381-010

Lembaga Studi Cinta dan Kemanusiaan serta Pusat Pelatihan Bisnis dan Humaniora (2011). Satu dari Tiga Mahasiswi Yogyakarta Hamil Diluar Nikah. Diakses dari https://www.kompasiana.com/

Mayasari, F., \& Hadjam, M. N. R. (2000). Perilaku seksual remaja dalam berpacaran ditinjau dari harga diri berdasarkan jenis kelamin. Jurnal Psikologi, 27(2), 120-127.

Mudzusi, A. H., \& Asgedom, T. (2016). The prevalence of risky sexual behaviours amongst undergraduate students in Jigjiga University, Ethiopia. health sa gesondheid, 21(1), 179186. http://dx.doi.org/10.1016/j.hsag.2015.11.002

Musdalifa, M. (2017). Kebutuhan afiliasi dan nomophobia mahasiswa universitas negeri makassar. (Doctoral dissertation, Universitas Negeri Makassar).

Mu'tadin, Z. (2002). Pendidikan seksual pada remaja. http://e-psikologi.com. Diakses tanggal 7 Mei 2019

Notoatmodjo, S. (2007). Promosi kesehatan dan ilmu perilaku. Jakarta: Rineka Cipta.

Nupus, P. K. (2017). Kebutuhan afiliasi pada remaja ditinjau dari jenis kelamin. (Doctoral dissertation, University of Muhammadiyah Malang).

Nurhayati, A., Fajar, N. A., \& Yeni, Y. (2017). Determinan perilaku seksual pranikah pada remaja SMA Negeri 1 Indralaya Utara. Jurnal Ilmu Kesehatan Masyarakat, 8(2).

Papalia, D. E., Olds, S. W., \& Feldman, R. D. (2008). Human development. McGraw-Hill.

Peplau, L.A., \& Perlman, D. (1982). Loneliness: a source book of current, theory, research and therapy. Toronto: John Wiley \& Sons. Inc.

Rahardjo, W., Citra, A. F., Saputra, M., Damariyanti, M., Ayuningsih, A. M., \& Siahay, M. M. (2017). Perilaku seks pranikah pada mahasiswa: menilik peran harga diri, komitmen hubungan, dan sikap terhadap perilaku seks pranikah. Jurnal Psikologi, 44(2), 139-152.

Rahman, A. A., Rahman, R. A., Ismail, S. B., Ibrahim, M. I., Ali, S. H., Salleh, H., \& Wan. A. M. (2015). Factors associated with attitude toward premarital sexual activities among school-going adolescents in Kelantan, Malaysia. Asia Pacific Journal of Public Health, 27(2), NP1549-NP1556.

Ratnasari, S., \& Suleeman, J. (2017). Perbedaan regulasi emosi perempuan dan laki-laki di perguruan tinggi. Jurnal Psikologi Sosial, 15(1), 35-46.

Rinjani, H., \& Firmanto, A. (2013). Kebutuhan afiliasi dengan intensitas mengakses facebook pada remaja. Jurnal Ilmiah Psikologi Terapan, 1(1),76-85.

Rosdarni, R., Dasuki, D., \& Waluyo, S.D. (2015). Pengaruh faktor personal berpengaruh terhadap perilaku seksual pranikah pada remaja di kota kendari provinsi sulawesi tenggara. Kesmas: National Public Health Journal, 9(3), 214-221.

Santrock, J. W. (2002). Life span development. Alih Bahasa: Juda Damanik \& Achmad Chusain. 
Cognicia

http://ejournal.umm.ac.id/index.php/cognicia
ISSN 2658-8428

2020, VOL. 8, NO. 1, 157-169

Jakarta: Erlangga.

. (2012). Life-span development (perkembangan masa hidup edisi 13 jilid 2, penerjemah:

widyasinta,b). Jakarta: Erlangga.

Sarlito, S. W. (2012). Psikologi Remaja. Jakarta: PT. Raja Grafindo Persada.

Sarwono, S. W. (1994). Psikologi remaja. Ed 1. Cet 3. Jakarta: PT Raja Grafindo Persada.

Sekaran, U. (2006). Metodologi penelitian untuk bisnis, Edisi Keempat. Jakarta: Penerbit Salemba Empat.

Setiawan, R., \& Nurhidayah, S. (2008). Pengaruh pacaran terhadap perilaku seks

pranikah. SOUL: Jurnal Ilmiah Psikologi, 1(2), 59-72.

Siswoyo, D. (2007). Ilmu pendidikan. Yogyakarta: UNY Press.

Soekanto, S. (2002). Sosiologi suatu pengantar. Jakarta: PT. Raja Grafindo Persada.

Sugiyono. (2014). Metode penelitian pendidikan pendekatan kuantitatif, kualitatif dan RED. Bandung:

Alfabeta.

(2016). Metode penelitian kuantitatif, kualitataif, dan kombinasi (mixed methods).

Bandung: Alfabeta. (2017). Metode penelitian kuantitatif, kualitatif, dan rEd. Bandung: Alfabeta.

Survey Demografi dan Kesehatan Indonesia (2017). Gunung Es Perilaku Seksual Pranikah Di Kalangan Remaja. Diakses dari https://health.detik.com/berita-detikhealth/

Susanti, T. D. (2008). Perbedaan perilaku seksual remaja dalam berpacaran di kos antara remaja yang kos dengan induk semang dan remaja yang kos tanpa induk semang. Skripsi, Program Studi Psikologi Fakultas Psikologi. Universitas Sanata Dharma Yogyakarta.

Suyanto, B., \& Ariadi, S. (2004). Sosiologi, teks pengantar dan terapan. Jakarta: Kencana.

Suwarni, L. (2009). Pengaruh monitoring parental dan teman sebaya terhadap perilaku seks pranikah remaja di kota pontianak. Jurnal Promosi Kesehatan Indonesia. Universitas Diponegoro.

Shaluhiyah, Z., Suryoputro, A., \& Setyawati, A. (2017). The Needs of Information Services on Reproductive Health, STIs and HIV in Middle Adolescence. KEMAS: Jurnal Kesehatan Masyarakat, 12(2), 233-242.

Uecker, J. E. (2015). Social context and sexual intercourse among first-year students at selective colleges and universities in the United States. Social science research, 52, 59- 71.

Ursachi, G., Horodnic, I. A., \& Zait, A. (2015). How reliable are measurement scales? External factors with indirect influence on reliability estimators. Procedia Economics and Finance, 20, 679-686.

Wardhani, V. (2006). Gambaran kualitas hidup dewasa muda berstatus lajang melalui adaptasi instrumen WHOQOL-BREF dan SRPB (Doctoral dissertation, FPsikologi-UI).

Winarsunu, T. (2009). Statistik dalam penelitian psikologi dan pendidikan. Malang: Universitas Muhammadiyah Malang.

Yanica, N. L. (2014). Korelasi antara kebutuhan afiliasi dan keterbukaan diri dengan intensitas menggunakan jejaring sosial pada siswa kelas VII SMP N 15 Yogyakarta. Skripsi Universitas NegeriYogyakarta. 